\title{
Transplant-Related Carcinoma
}

National Cancer Institute

\section{Source}

National Cancer Institute. Transplant-Related Carcinoma. NCI Thesaurus. Code C27633.

A carcinoma that arises in a patient with a history of organ transplantation. 